\title{
ADVANTAGES OF MANUAL LIQUID-BASED CYTOLOGY IN CERVICOVAGINAL SMEARS WITH SPECIAL EMPHASIS ON CELL BLOCK
}

\author{
Shweta Kulkarni ${ }^{1}$, Nandini Manoli², Nandish Manoli ${ }^{3}$ \\ ${ }^{1}$ Senior Resident, Department of Pathology, Indira Gandhi Institute of Child Health, Bengaluru. \\ 2Professor, Department of Pathology, JSS Medical College, A Constituent of JSS University, India. \\ ${ }^{3}$ Professor, Department of Obstetrics and Gynaecology, JSS Medical College, A Constituent of JSS University, India.
}

ABSTRACT

\section{BACKGROUND}

Cervical cancer is the second most common cancer among women worldwide and the leading cause of cancer deaths amongst women. Early detection is possible by cervical screening. Liquid-based cytology and Cell blocks prepared from residue can be useful adjuncts to smears for establishing a more definitive cytopathological diagnosis.

\section{MATERIALS AND METHODS}

This is a descriptive study. The present study was undertaken to prepare liquid-based smears and cell blocks from Liquid-based cytology specimens to aid in the diagnosis of Pap smears and to correlate with histopathology wherever possible. The study was undertaken in the period from July 2011 to July 2013. Total of 60 conventional Pap smears were obtained. Sample size was selected conveniently. In the present study, 60 cell blocks were prepared from MLBC specimen collected in a liquid fixative. Results were compared with cytology smears and histopathological correlation was obtained in 19 cases.

\section{RESULTS}

In the present study, out of 60 cases of cell blocks, 10 cases had no deposit. Of the other 50 cases, 7 cases (14\%) were neoplastic and 43 (86\%) were non-neoplastic. The sensitivity and specificity of cell block, LBC and CPS were $75 \%$ and $93 \%, 66 \%$ and $84 \%$, $50 \%$ and $70 \%$ respectively for neoplastic lesions of cervix. Concordance Rate of CB/Histopathology vs. CPS/Histopathology is $74 \%$ vs. $54 \%$.

\section{CONCLUSION}

In the present study, we found that cell blocks prepared from the LBC specimens aid in the diagnosis of neoplastic lesions of cervix and are particularly valuable in distinguishing carcinoma cervix from intraepithelial lesions. Cell blocks can be further subjected to ancillary tools like immunohistochemistry and HPV- DNA testing.

\section{KEYWORDS}

Cell Block, MLBC, Carcinoma Cervix.

HOW TO CITE THIS ARTICLE: Kulkarni S, Manoli N, Manoli N. Advantages of manual liquid-based cytology in cervicovaginal smears with special emphasis on cell block. J. Evolution Med. Dent. Sci. 2017;6(88):6103-6108, DOI: 10.14260/jemds/2017/1326

\section{BACKGROUND}

Cervical cancer is the fourth most common cancer affecting women worldwide, with 5,28,000 new cases every year and is most notable in the lower-resource countries of sub-Saharan Africa. ${ }^{1}$ Cervical cancer causes more than one quarter of a million deaths per year as a result of grossly deficient treatments in many developing countries. ${ }^{2}$ Liquid-based cytology has recently become an alternative to conventional Pap smears in the detection of intraepithelial lesions as well as in invasive carcinoma of the uterine cervix. ${ }^{1}$ The traditional cytology preparation consists of a smear, which is routinely used but often in combination with alternative and more newly introduced technique(s), including cell blocks and liquid-based cytology (LBC), respectively. LBC yields a thin layer of cells dispersed over a fixed area, generally by using automated systems that standardise slide preparation, transportation, and fixation. ${ }^{3}$

'Financial or Other Competing Interest': None.

Submission 14-09-2017, Peer Review 25-10-2017,

Acceptance 31-10-2017, Published 06-11-2017.

Corresponding Author:

Dr. Shweta Kulkarni,

Banashankari Balaji Paradise, Flat no 203,

Kanakapura Road, Behind Government School Playground,

Yelachenahalli, Bangalore-560078.

E-mail: drshwetakulkarni@gmail.com

DOI: $10.14260 /$ jemds $/ 2017 / 1326$
Several reports have discussed its benefits to cytologic diagnosis. In most of these reports, a significant rise in sensitivity was achieved with liquid-based procedures, without major losses in specificity.., 5

Cell blocks prepared from residual tissue fluids and fineneedle aspirations can be useful adjuncts to smears for establishing a more definitive cytopathological diagnosis and they can be a valuable diagnostic adjunct in cytological preparation in selected fluid-based cervicovaginal specimens. ${ }^{6}$

\section{Objectives of the Study}

The Aims and Objectives of the Study are-

1. To study cytomorphology of Pap smears using the manual Liquid-based cytology (MLBC) and conventional Pap smear method.

2. To study cell block preparations of deposits got by MLBC.

3. To determine the utility of cell block preparation in improving diagnostic accuracy of liquid preparations.

4. To correlate these cases with histopathology wherever possible.

\section{MATERIALS AND METHODS}

This was a descriptive study. The present study was undertaken to prepare liquid-based smears and cell blocks from Liquid-based cytology specimens to aid in the diagnosis 
of Pap smears and to correlate with histopathology wherever possible. The study was undertaken in the period from July 2011 to July 2013.

\section{Sample Size}

Total of 60 Conventional Pap smears were obtained. Sample size was selected conveniently.

Cell blocks were prepared for 60 cases with adequate material in LBC. Among 60 cases, histopathological correlation was obtained in 19 cases.

\section{Source of Data}

Samples of MLBC of which cell block preparation is made are collected from about 60 patients in the age group of 20 to 70 years with gynaecological complaints like white discharge $\mathrm{P} / \mathrm{V}$ and bleeding $\mathrm{P} / \mathrm{V}$ attending the Gynaecology Outpatient Clinic at JSS Hospital, Mysore.

All the patients were clinically examined in detail according to the proforma and details of other relevant laboratory investigations were collected only if necessary.

\section{Sampling Procedure}

1. Samples were collected by a plastic Ayre's spatula from the transformation zone of the cervix by $360^{\circ}$ rotation around the cervix.

2. The sample was then transferred on a clean glass slide and fixed by a spray fixative and after fixation they are stained by Papanicolaou (Pap) stain.

3. Another rotation is taken and this sample is transferred to the liquid fixative. It was centrifuged at $2000 \mathrm{rpm}$ for 5 minutes. The supernatant was decanted and excess fixative was blotted.

4. 1-2 $\mathrm{mL}$ of polymer solution was added to the deposit. It was again centrifuged at $2000 \mathrm{rpm}$ for 5 minutes. The deposit was pipetted in a circular motion on to a glass slide. The LBC slides were placed on a metal tray and dried in a hot air oven at 50 degrees (Indirect heat fixation) and further fixed by dipping in $95 \%$ alcohol for 5 minutes. Stained with the conventional Pap stain.

5. The cell block is prepared from the liquid fixative deposit by adding equal amount of cell block fixative $(10 \%$ formalin and 95\% alcohol), got during MLBC procedure.

6. The cell block obtained is routinely processed as a histopathological tissue and stained with routine haematoxylin and eosin stain. The conventional smears, MLBC smears and cell blocks were screened and compared.

\section{Fixation of Smears}

Spray fixatives were used to immediately fix the smears and to protect the smears from drying by forming an invisible film on the surface of the slides and sprayed immediately after processing of smears.

The Bethesda system 2001 was used for reporting cervical cytology for both groups.

Cytohistological correlation was done in those cases in which a colposcopic biopsy was also done.

\section{Inclusion Criteria}

All the adequate samples sent for cytological screening.

\section{Exclusion Criteria}

All the unsatisfactory and inadequate samples of manual Liquid-based cytology sent with conventional Pap smears.

\section{Statistical Analysis}

All the statistical calculations were done through SPSS for windows (v 16.0).

Sensitivity and specificity of conventional smears, LBC smears and cell blocks were calculated and compared.

1. Positive predictive value for diagnosing neoplastic lesions on cell blocks: 75\%.

2. Efficacy of cell blocks in the diagnosis of neoplastic lesions: $89 \%$.

3. Concordance Rate of CB/Histopathology vs. CPS/ Histopathology is $74 \%$ vs. $54 \%$.

\section{RESULTS}

Age group of patients ranged from 20 years to 60 years with the youngest patient aged 23 years and oldest 55 years. Mean age was 35.9 years. Mean age for neoplastic lesions was 40 years. Majority of the patients were in the age group of 36-45 years.

Of 60 cases in our study, 10 cases had no deposit and cell block diagnosis could not be offered. This inadequate material may be due to sampling errors. Of the rest 50 cases with adequate material, 7 were neoplastic and 43 were nonneoplastic.

\section{Cytology}

Of 60 cases of conventional Pap smears, majority were inflammatory (17 cases) and NILM (17 cases), other cases included BV (4 cases), TV (5 cases), HSIL (3 cases), LSIL (2 cases), AGUS (1 case), atrophic (1 case), Leptothrix (1 case), Herpes (1 case), HPV (1 case) and 7 cases were unsatisfactory.

\section{MLBC}

LBC smears were done for 39 cases. Two cases had inadequate material.

Of 39 LBC smears, majority of the cases were diagnosed as inflammatory (13 cases). Other cases included NILM (12 cases), TV (1 case), BV ( 3 cases), atrophic ( 2 case), HPV (1 case), LSIL (2 cases) and HSIL (cases). For 21 cases, we processed entire MLBC material from the liquid fixative for cell blocks preparation without preparing LBC smears, to obtain adequate material for cell blocks (Table 1).

\section{Cell Block}

Neoplastic lesions included squamous cell carcinoma SCC (1 case), dysplasia (2 cases), carcinoma in situ (4 cases). 43 nonneoplastic lesions include chronic polypoid endocervicitis (CPEC- 10 cases), Koilocytes (3 cases), chronic cervicitis (12 cases), normal study (10 cases), acute-on-chronic cervicitis ( 7 cases), only haemorrhage (1 case). (Table 1 ).

In our study, 10 cases of the cell blocks had no deposits. Of these, only 3 cases were reported as satisfactory on conventional smears and 7 cases were unsatisfactory on conventional smears and had inadequate samples for MLBC smear. Cases reported as no deposits were maximum when MLBC had inadequate material and were minimum when LBC 
smears were not done and sediment was directly processed for cell blocks.

Comparison of Neoplastic lesions diagnosed on cell blocks with CPS and MLBC-

7 cases of cell blocks were diagnosed as neoplastic including carcinoma in situ. They included squamous cell carcinoma SCC (1 case), dysplasia (2 cases), carcinoma in situ CIN (4 cases).

SCC was diagnosed as HSIL in CPS and LBC. 1 case of dysplasia was diagnosed as inflammatory on CPS and MLBC and other case of dysplasia was diagnosed as HSIL on CPS and MLBC. 1 case of CIN was unsatisfactory on CPS and 3 cases of CIN were diagnosed as HSIL and LSIL.

This shows that cellular architecture is better preserved and neoplastic lesions which are underdiagnosed on CPS and MLBC can be correctly diagnosed on cell blocks. (Table 3).

Comparison of cell block diagnosis with histopathology-

Histopathologic correlation was obtained in 19 cases. Of these, 4 cases were neoplastic and 15 cases were nonneoplastic. Of 19 cases, cell block diagnosis correlated with histopathology in 14 cases.

\begin{tabular}{|c|c|c|c|c|}
\hline $\begin{array}{l}\text { SI. } \\
\text { No. }\end{array}$ & $\begin{array}{l}\text { Cell Block } \\
\text { Diagnosis }\end{array}$ & $\begin{array}{l}\text { No. of } \\
\text { Cases }\end{array}$ & $\begin{array}{c}\text { MLBC } \\
\text { Diagnosis }\end{array}$ & $\begin{array}{l}\text { No. of } \\
\text { Cases }\end{array}$ \\
\hline 1 & $\begin{array}{c}\text { Chronic } \\
\text { cervicitis(CC) }\end{array}$ & 12 & NILM & 11 \\
\hline 2 & CPEC & 10 & Inflammatory & 13 \\
\hline 3 & Normal study & 10 & Inadequate (IA) & 2 \\
\hline 4 & $\begin{array}{c}\text { Acute-on-chronic } \\
\text { cervicitis(ACC) }\end{array}$ & 7 & Atrophic & 2 \\
\hline 5 & Koilocytes & 3 & BV & 3 \\
\hline 6 & Only haemorrhage & 1 & HERPES & 1 \\
\hline 7 & SCC & 1 & TV & 1 \\
\hline 10 & CIN 3 & 1 & HPV & 1 \\
\hline 8 & CIN 2 & 2 & HSIL & 3 \\
\hline 9 & CIN 1 & 1 & LSIL & 2 \\
\hline 10 & Dysplasia & 2 & - & - \\
\hline 11 & No deposit & 10 & - & - \\
\hline 12 & Total & 60 & Total & 39 \\
\hline \multicolumn{5}{|c|}{$\begin{array}{l}\text { Table 1. Morphological Distribution of Cases Diagnosed or } \\
\text { MLBC and Cell Block }\end{array}$} \\
\hline
\end{tabular}

\begin{tabular}{|c|c|c|c|}
\hline Sl. No. & CPS Diagnosis & LBC Diagnosis & CB Diagnosis \\
\hline 1 & HSIL & HSIL & SCC \\
\hline 2 & LSIL & HSIL & CIN3 \\
\hline 3 & LSIL & - & CIN2 \\
\hline 4 & LSIL & - & CIN2 \\
\hline 5 & Unsatisfactory & LSIL & CIN1 \\
\hline 6 & Inflammatory & Inflammatory & Dysplasia \\
\hline 7 & HSIL & HSIL & Dysplasia \\
\hline Total & 7 & 5 & 7 \\
\hline Table 2. Comparison of Neoplastic Lesions Diagnosed on \\
\multicolumn{4}{|c}{ Cell Blocks with CPS and MLBC } \\
\hline
\end{tabular}

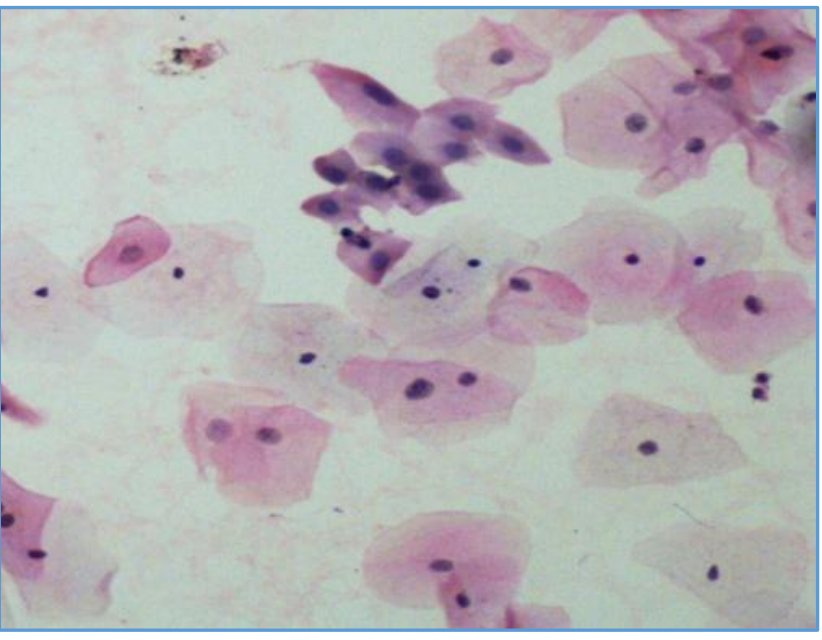

Figure 1. MLBC (Pap, 20 X)-Smear shows Squamous Metaplastic cells and Normal Looking Squamous Cells

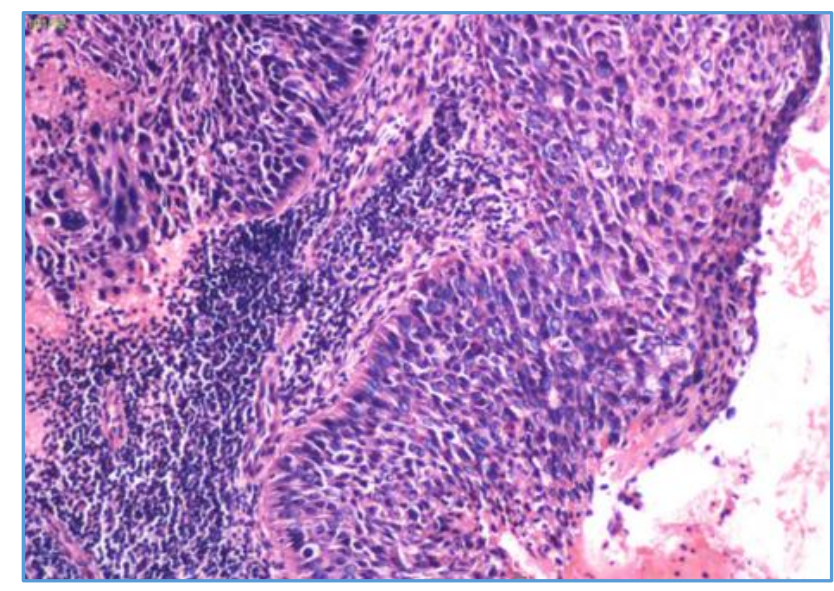

Figure 2. Cell Block. (H \& E, 40X).CIN 3: Section studied shows Stratified Squamous Epithelium Displaying Fullthickness Dysplasia and areas of Inflammatory Cell Infiltrate

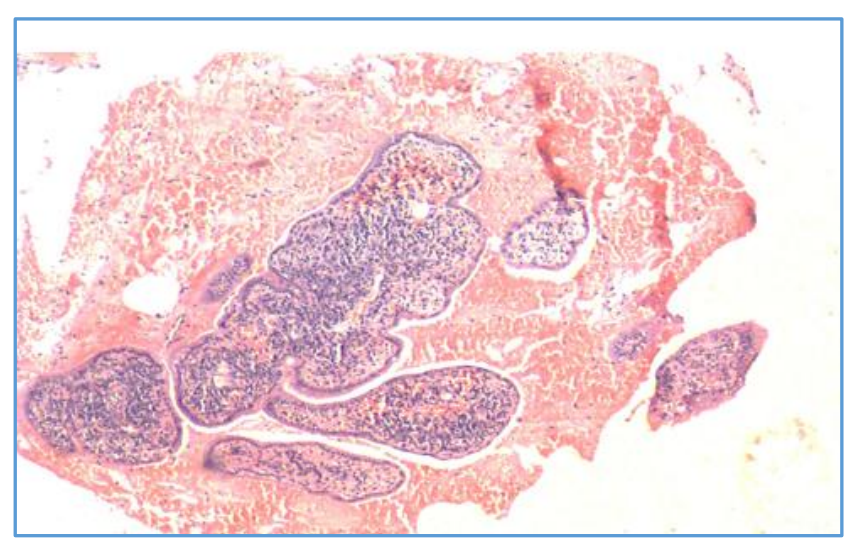

Figure 3 Cell block. (H \& E, 10 X). Section studied shows Features of Chronic Polypoid Endocervicitis with Inflammatory Cells, Areas of Haemorrhage. 


\section{DISCUSSION}

Cancer of the uterine cervix has been the most important cancer in women in India over the past two decades. ${ }^{7}$

High-quality cervical screening can contribute to a reduction in the incidence and mortality of cervical cancer; however, cancer can develop even in screened women due to patient management errors, sampling errors and interval carcinomas. ${ }^{8}$ Though its use has resulted in dramatic decline in the mortality and morbidity rates of cervical cancer, CPS has its own limitations.

Like all screening tests, the cervical smear or any new cytological method are not perfect. Thus, in considering a new screening methodology it is important to consider its limitations alongside those of existing methods. ., $10^{2}$

False negatives in CPS may be related to inadequate sampling, inadequate transfer of sample onto glass slide or deficiencies in microscopic assessment of the slide. A falsenegative Papanicolaou smear result is defined as "the failure to demonstrate abnormality by Papanicolaou examination in a woman who has disease".

The diagnosis of cancers are missed due to sampling errors like incomplete sampling of the transformation zone, a poorly prepared slide with drying artifact or clumping of cells and failure of the cytotechnologist to detect the presence of abnormal cells on the slide. ${ }^{9,10,11}$

One way to recognise the different appearances of cells in the liquid-based system is to look at paired split-sample cases and to perform cell block sections of residual materials in the samples.

MLBC is a cost-effective method which needs no expensive machine, uses only centrifuge and provides an improved slide preparation technique. MLBC also provides material for cell block preparation from residual samples. 8,12

In our study, we used a similar improvised method of MLBC. Material for MLBC was collected using plastic spatulas and simultaneous cervical scrape smears were made and stained with Pap stain. Cell blocks were prepared after centrifugation of this material in the fixative.1,5

The age range in our study was 23 years to 55 years. In our study, the mean age range of neoplastic lesions was 40 years which is comparable to a study by Wei $Q$ et al in which the mean age of HSIL patients was 42.2 years and that of SCC patients was 45.4 years. ${ }^{13}$

Unlike many other cancers, cervical cancer occurs early and strikes at the productive period of a woman's life and only $5 \%$ of women in developing countries undergo cervical screening compared with $40-50 \%$ in the developed world. ${ }^{14}$

Liquid-based cytology (LBC) and conventional Pap smears in diagnosing neoplastic lesions:

In our study, we found that sensitivity of MLBC vs. CPS was $67 \%$ vs. $50 \%$ and specificity was $84 \%$ vs. $71 \%$. Thus, MLBC is more sensitive and specific for the diagnosis of neoplastic lesions as compared to CPS.

The possible explanations for improved sensitivity of MLBC may be improved sample collection, reduction in obscuring elements and better preservation of abnormal cells on the slide allowing for more definitive categorisation of abnormal cells as intraepithelial lesions. ${ }^{11}$

The process of Liquid-based cytology better preserves cellular structure, prevents drying artifact and removes red blood cells and mucus.
The false negative outcomes of CPS appear either due to the poor quality of the conventional smears or by using some inadequate removing device and the false positive ones may be due to air drying artefacts of the smears .15,16

In our study, out of 60 cases, 10 cases had no deposits on cell blocks due to low cellularity. Liquid-based cervicovaginal specimens are relatively less cellular than their nongynaecologic counterparts with many individual scattered cells. Because of this, adequate cellularity within the cell block sections is difficult to achieve.

This Problem of Inadequate Cellularity can be evaluated by using Following Features ${ }^{10}$

1. Concentration and alignment of singly scattered cells in a narrow plane adjacent and parallel to the cutting surface of the cell block.

2. Inclusion of a beacon-like dark AV-marker as a signpost. In few of our cases, we entirely processed the material of MLBC without splitting the specimen, which yielded better results.

\section{Possible Causes of False-Negative Pap Tests}

- No atypical cells in the preparation (incorrect sampling) $=60-75 \%$.

- Atypical cells are present but cannot be identified due to poor fixation and/or overlapping.

- Atypical cells are present, but are being overlooked by the Screener ("screening error").

- Atypical cells are present and are identified but not correctly interpreted, thus they are falsely judged.

\section{Diagnostic Aid and Accuracy of Cell Blocks}

In present study, $14 \%$ of cases were diagnosed as malignant and $86 \%$ of cases were benign. We found that cell block showed an increase in both sensitivity and specificity in the diagnosis of neoplastic conditions of cervix.

The increased sensitivity of cell blocks in the diagnosis of malignant conditions of cervix may be due to better preservation of cytomorphologic features, better staining characteristics of the nucleus, nucleoli, and cytoplasm, clear recognition of nuclear and cytoplasmic features. When used as an adjunct to the smear, CBs aid in providing a reliable diagnosis of cervical cancer in the majority of the clinically suspected cases and thus the biopsy load can be reduced significantly in resource-poor settings. ${ }^{17}$

In the present study, one case which was diagnosed as HSIL turned out to be SCC in cell blocks and a case of inflammatory smear in Pap was reported as dysplasia in cell blocks.

The sensitivity and specificity of Pap smear remains low even in the hands of experts, inter-observer variability still is significant and an irreducible false-negative rate inherent in the process.

For a cytopathologist, it is difficult to make an accurate cytological diagnosis due to thick tissue fragments. The widespread use of MLBC enables proper screening of tissue fragments obtained from cell block preparations. ${ }^{18}$ Cell blocks are an adjunctive technique to LBC, and various methods to prepare cell blocks have been reported, primarily inverted filter sedimentation, and plasma and agar methods. Despite faithful yearly examinations, approximately $50 \%$ of the women who develop carcinoma of the cervix will have no 
abnormal cells present on their retrospectively reviewed smear and the remainder of patients will have cells present that were not detected due to screening or interpretive errors. ${ }^{19}$

It was believed that in most of the specimens, the discrepancy between findings in cytology samples and findings in cell blocks was attributable to the lack of diagnostic cells in the residual material from which the cell blocks were prepared.

The morphological details including preservation of the architectural pattern like cell balls, papillae and threedimensional clusters, excellent nuclear and cytoplasmic details, and individual cell characteristics can also be obtained with the CB method. The tissue fragments can easily be interpreted in a biopsy-like fashion. ${ }^{17}$

Some consider cervical biopsy to be the gold standard for diagnosing cervical lesions, but others have suggested that cytologic analysis is the more accurate technique.

Since a large majority of lesions identified were LSILs, a repeat Pap smear in these cases represented a more costeffective strategy than cell block preparation, although a cell block preparation may be useful in selected cases. Smears with large clusters or true tissue fragments of abnormal cells are better visualised using the cell block technique.20,21

Therefore, the use of cell blocks as an adjunct to the diagnosis of challenging cytologic cases has the potential to reduce the rate of both false-positive and false-negative results with the Pap test.

\section{Cyto-histo Correlation}

In our study, cell blocks agreed with histopathology in 74\% of cases as compared to $64 \%$ in case of Pap smears.

Similar findings were found in a study, in which the tissue, cytology, and cell block findings were concordant in 15 cases $(28 \%)$. Tissue agreed more closely with the cell block than with the cytology in eight cases, and more closely with the ThinPrep cytology. ${ }^{21}$

\section{CONCLUSION}

Liquid-based cytology includes preparation and evaluation of cells collected from liquid fixative, it enables cells to be suspended in monolayer. The advent of thin layer cytology creates a new opportunity for the use of cell blocks in gynaecologic area. The cell blocks prepared from MLBC specimens increase the diagnostic accuracy of Pap smears.

Cell blocks not only reduce both the false positives and false negatives, but also augment the sensitivity of smear tests.

Cell blocks provide additional information like epithelial stromal interface and tumour necrosis which are helpful in providing definitive diagnosis of SCC. In such cases, cell blocks help to distinguish between HSIL and SCC. Characterisation of some lesions which may be difficult in the cytology smears, may be facilitated by the histologic sectioning of the cell blocks. Thus, cell blocks also help in reducing the biopsy load in the resource limited settings.

The disadvantages lie in sample collection, increased turn over time and additional costs for immunohistochemistry.

Our study confirms that Liquid-based cytology with cell blocks can be advantageously added to the conventional smears and with better sampling methods, cell blocks can prove to be a useful tool in the field of cytopathology.

\section{REFERENCES}

[1] Cooper DB, McCathran CE. Cervical, Dysplasia. StatPearls Publishing 2017.

[2] Saqi A. The state of cell blocks and ancillary testing: past, present and future. Arch Pathol Lab Med 2016;140(12):1318-22.

[3] Manoli N, Manoli N, Kamath A, et al. Manual Liquidbased cytology method for detection of cervical cancer: recent concepts in cytology for early detection of cervical cancer. Cancer Research Journal 2016;4(4): 58-68.

[4] Alves VAF, Bibbo M, Schemitt FCL, et al. Comparison of manual and automated methods of liquid-based cytology. A morphologic study. Acta Cytol 2004;48(2):187-93.

[5] Lee JM, Kelly D, Gravitt PE, et al. Validation of a lowcost, liquid based screening method of cervical intraepithelial neoplasia. Am J Obstet and Gynecol 2006;195(4):965-70.

[6] Richard K, Dziura B, Hornish A. Cell block preparation as a diagnostic technique complementary to fluid based monolayer cervicovaginal specimens. Acta cytol 1999;43(1):69-73.

[7] Nandakumar A, Ramnath T, Chaturvedi M. The magnitude of cancer cervix in India. Indian J Med Res 2009;130(3):219-21.

[8] Klinkhamer PJ, Meerding WJ, Rosier PF, et al. Liquidbased cervical cytology. Cancer 2003;99(5):263-71.

[9] Mulay K, Swain M, Patra S, et al. A comparative study of cervical smears in an urban hospital in India and a population-based screening program in Mauritius. Indian J of Pathol Microbiol 2009;52(1):34-7.

[10] Yeoh GP, Chan KW. Cell block preparation on residual ThinPrep sample. Diagnostic Cytopathol 1999;21(6):427-31.

[11] Bernstein SJ, Sanchez-Ramos L, Naubisi B. Liquid based cytological smear study and conventional Papanicolaou smears: a meta-analysis of prospective studies comparing cytologic diagnosis and sample adequacy. Am J Obstet Gynecol 2001;185(2):308-17.

[12] Kavatkar AN, Nagwanshi CA, Dabak SM. Study of a manual method of liquid-based cervical cytology. IJPM 2008;51(2):190-4.

[13] Wei Q, Liu J, Zhang Z, et al. Morphological features of cell blocks prepared from residual liqui-PREP samples can distinguish between high-grade squamous intraepithelial lesions and squamous cell carcinomas. Acta Cytol 2011;55(3):245-50.

[14] Kaarthigeyan K. Cervical cancer in India and HPV vaccination. Indian $\mathrm{J}$ Med Paediatr Oncol 2012;33(1):7-12.

[15] Popescu CF, Badulescu A, Badulescu F, et al. Preliminary study concerning the cytoscreen system importance (Liquid-based cytology) in gynecologic cytology. Romanian Journal of Morphology and Embryology 2005;46(1):23-7. 
[16] Johnson T, Maksem JA, Belsheim BL, et al. Liquidbased cervical-cell collection with brushes and wooden spatulas: a comparison of 100 conventional smears from high-risk women to liquid-fixed cytocentrifuge slides, demonstrating a cost-effective, alternative monolayer slide preparation method. Diagn Cytopathol 2000;22(2):86-91.

[17] Gupta S, Halder K, Khan VA, et al. Cell block as an adjunct to conventional Papanicolaou smear for diagnosis of cervical cancer in resource-limited settings. Cytopathology 2007;18(5):309-15.

[18] Beerman H, van Dorst EB, Kuenen-Boumeester V, et al. Superior performance of liquid-based versus conventional cytology in a population-based cervical cancer screening program. Gynecologic Oncology 2009;112(3):572-6.
[19] Keyhani-Rofagha S, Vesey-Shecket M. Diagnostic value, feasibility and validity of preparing cell blocks from fluid based gynecologic cytology specimens. Cancer Cytopathology 2002;96(4):204-9.

[20] Kabbani W, Raisanen J, Thomas S, et al. Cell block findings from residual PreservCyt samples in unsatisfactory ThinPrep Paps: no additional benefit. Diagn Cytopathol 2002;27(4):238-43.

[21] Diaz-Rosario LA, Kabawat SE. Cell block preparation by inverted filter sedimentation is useful in the differential diagnosis of atypical glandular cells of undetermined significance in ThinPrep specimens. Cancer Cytopathology 2000;90(5):265-72. 